\title{
An Analysis of Errors in English Writing of Sinhala Speaking Undergraduates
}

\section{Rohan Abeywickrama}

Department of Languages, Faculty of Social Sciences and Languages, Sabaragamuwa University of Sri Lanka, P.O Box 02, Belihuloya, SriLanka.roh@sab.ac.lk

\begin{abstract}
Error analysis is a type of linguistic analysis that focuses on the errors learners make. It consists of a comparison between the errors made in the Target Language (TL) and that TL itself. For learners themselves, errors are 'indispensable,' since the making of errors can be regarded as a device the learner uses in order to learn. Researchers are interested in errors because they are believed to contain valuable information on the strategies that learners use to acquire a language. Hence, an error analysis is the best tool for describing and explaining errors made by speakers of other languages in order to know the sources of these errors and the reasons behind their continued occurrence year after year with different groups of learners.
\end{abstract}

This study focuses on errors in English essay writing of Sinhala speaking undergraduates in order to identify whether the L1 transfer is the major cause for errors in English writing of Sinhala undergraduates. If this were to be true, then it could be concluded that the reason behind all those errors is Negative L1 transfer/ Mother Tongue interference. This paper further attempts to identify and describe Sinhala speaking undergraduates' errors in English essay writing and thereby make efforts to minimize the problems encountered in their English writing. Target Population were the selected Sinhala speaking undergraduates who are offering English as a Second language for their BA (General) Degree at the Universities of Kelaniya, Peradeniya and the Sabaragamuwa University of Sri Lanka.

For the selection of a corpus of language, following the guidelines offered by (Ellis, 1995) samples of written assignments were collected from 60 students who are in the first and the second academic years of their degree programmes. These students were provided with the topics 'An Unforgettable Day in My Life' or 'My University Life' and asked to write on them in 200 to 250 words. They were given sufficient time to write (Ellis, 1997). They started with an outline, then a first draft and a final draft.

This highly objective and outcome-oriented investigation reflects negative L1 transfer/interference is not the major cause for errors in the English writings of Sinhala speaking undergraduates. This would enable the academic researchers, language teachers, linguists to build up a further discussion on errors of Sinhala speakers' English writing.

Key words: Errors, Undergraduates, Sinhala, Second Language, L1 Transfer 


\section{Introduction}

'Systematically analyzing errors made by language learners makes it possible to determine areas that need reinforcement in teaching' (Corder, 1974).

Error analysis is a type of linguistic analysis that focuses on the errors learners make. It consists of a comparison between the errors made in the Target Language (TL) and that TL itself. Corder (1967) is the 'Father' of Error Analysis. It was with his article entitled 'The Significance of Learner Errors' that EA took a new turn. He contended that those errors are 'important in and of themselves.' For learners themselves, errors are 'indispensable,' since the making of errors can be regarded as a device the learner uses in order to learn. Gass and Selinker (2001) defined errors as 'red flags' that provide evidence of the learner's knowledge of the second language. Researchers are interested in errors because they are believed to contain valuable information on the strategies that learners use to acquire a language (Richards, 1974; Taylor, 1975; Dulay and Burt, 1974). Moreover, according to Richards and Sampson (1974) "At the level of pragmatic classroom experience, error analysis will continue to provide one means by which the teacher assesses learning and teaching and determines priorities for future effort."

Before 1960s, when the behaviouristic viewpoint of language learning was prevailing, learner errors were considered something undesirable and to be avoided. It is because in behaviourists perspectives, people learn by responding to external stimuli and receiving proper reinforcement. A proper habit is being formed by reinforcement, hence learning takes place. Therefore, errors were considered to be a wrong response to the stimulus, which should be corrected immediately after they were made.

This belief of learning was eventually discarded by the well-known radically different perspective proposed by Chomsky (1957). He wrote in his paper against (Selikner, 1989) that human learning, especially language acquisition, cannot be explained by simply starting off with a 'tabula rasa' state of mind. He claimed that human beings must have a certain kind of innate capacity which can guide learner through a vast number of sentence generation possibilities and have a child acquire a grammar of that language until the age of five or six with almost no exception. He called this capacity "Universal Grammar" and claimed that it is this very human faculty that linguistics aims to pursue.

According to Corder (1974), error analysis has two objectives: one theoretical and another applied. The theoretical objective serves to "elucidate what and how a learner learns when he studies a second language." And the applied object serves to enable the learner "to learn more efficiently by exploiting our knowledge of his dialect for pedagogical purposes". The investigation of 
errors can be at the same time diagnostic and prognostic. It is diagnostic because it can present us the learner's state of the language (Corder, 1967) at a given point during the learning process and prognostic because it can inform course organizers to reorient language learning materials on the basis of the learners' current problems.

As an English teacher, the researcher is well aware of the fact that the Sinhala speaking undergraduates in the Faculty of Social Sciences and Languages: Sabaragamuwa University of Sri Lanka commit many errors in English writing.

The following quotation provides evidence.

William Wordsworth is Romantic poet. He is a nature lover. He use his experiences and uses beutiful image to create a these kind of poem. When we consider about poem 'I Wandered lonely as a colud' he visualizes the beauty of the nature. He not satisfy talking about nature. however he is believe neture can make a better world. Written by a Sinhala Speaking undergraduate - in Eng 121-2007 Semester I.

It is obvious that people communicate orally and/or in writing. "In spoken conversations with others, they make sense of the dialogue in a complex back-and-forth process of negotiation of meaning between speakers. In written texts, this back-and-forth negotiation is not possible. The sentence is written and it is read. Because there is no possibility of negotiating meaning of written documents, the inevitable problems of misunderstandings are exacerbated" (Penman, 1998). Hence, it is evident that writing is an intricate and complex task; it is the most difficult of the language abilities to acquire. Its level of difficulty varies between native speakers (NS) who think in the language used (in our case it will be English) and non-native speakers (NNS) who think in their own native language (in this case it will be Sinhala). While writing, non-native speakers have, in general, to think about all those rules they need to apply, rules that native speakers are supposed to have automatized. Therefore, non-native speakers are more prone to making mistakes and/or committing errors.

It is essential here to make a distinction between mistake and error; both Corder $(1967,1974)$ and James (1998) reveal a criterion that helps us to do so: it is the self-correctability criterion. A mistake can be self-corrected, but an error cannot. Errors are 'systematic,' i.e. likely to occur repeatedly and not recognized by the learner. Hence, only the teacher or researcher would locate them, the learner wouldn't (Selinker and Gass, 1994). And it is in this light that the researcher selected to focus on students' errors not mistakes.

Some of these students have been studying English for their whole lives and still, their errors are numerous. Hence, the researcher decided to conduct 
an error analysis- the best tool for describing and explaining errors made by speakers of other languages (Johanson, 1975) - in order to know the sources of these errors and the reasons behind their continued occurrence year after year with different groups of learners.

It is essential here to mention the fact that the language these students speak at home is mainly Sinhala, not English; hence, they are ESL students, however immersed in English they might be at school and at a university.'To use two languages familiarly and without contaminating one by the other is very difficult" (Johnson, 1761).

Can this fact account for the problems? Is our undergraduates' native language (L1) 'contaminating' their English (L2)? If this were to be true, then the reason behind all those errors is Negative L1 transfer/Mother Tongue interference. 'And the best way to discover such a transfer is through error analysis' (Sridhar, 1980). However, can transfer alone justify all the errors made?

\section{Research Problem}

"Is negative L1 transfer/interference the major cause for errors in the English writings of Sinhala speaking undergraduates?"

\section{Problem Statement}

Various researchers have concentrated on errors which demonstrate the influence of one's native language to second language acquisition. Before Corder's work, interference errors were regarded as inhibitory; it was Corder who pointed out that they can be facilitative and provide information about one's learning strategies. According to Hagège (1993) interference between L1 and L2 is observed in children as well as in adults. In adults it is more obvious and increases continuously, as a monolingual person gets older and the structures of his first language get stronger and impose themselves more and more on any other language the adult wishes to learn. In contrast, as regards children, interference features will not become permanent unless the child does not have sufficient exposure to L2. If there is sufficient exposure, then instead of reaching a point where they can no longer be corrected (as often happens with phonetics features), interference features can be easily eliminated.

This study focuses on errors in English essay writing of Sinhala speaking undergraduates in order to identify whether the L1 transfer is the major cause for errors in English writing of Sinhala undergraduates. 


\section{Rationale for the Study}

"Very surprisingly there are few published descriptions of how or what children learn. (There... is) little about what mistakes the children made and how these can be explained, or what generalizations and learning strategies the children seem to be developing" (Richards, 1974).

After having reviewed the literature, the researcher noticed that no large scale investigation which involves Sinhala speaking undergraduates' who have been learning English since childhood as a second language, had been conducted.

Consequence of that problems relating to the teaching of English as a second language of Sinhala speakers are continuously being discussed.

This sort of error analysis would really significant in three ways:

- to the teacher: they show a student's progress

- to the researcher: they show how a language is acquired, what strategies the learner uses.

- to the learner: he can learn from these errors.

This study would enable the academic researches, language teachers, and linguists etc. to build up a further discussion on errors of Sinhala speakers' English writing.

\section{Aims and Objectives of the Study}

To attempt to identify, describe and categorize errors in English essay writing of Sinhala speaking undergraduates and thereby make efforts minimize the difficulties encountered by them.

\section{Hypotheses}

Negative L1 transfer/interference is the major cause for errors in the English writings of Sinhala speaking undergraduates.

Negative L1 transfer/interference is not the major cause for errors in the English writings of Sinhala speaking undergraduates.

\section{Type of Research}

This highly objective and outcome oriented investigation is based on a research question. In this cross sectional study different groups of learners who are offering English as a second language for their BA Degree, were examined 
at the same time and the different learners were then be assumed to represent different stages of development.

\section{Target Population}

Selected Sinhala speaking undergraduates who are offering English as a second language for their BA (General) Degree at the Universities of Kelaniya, Peradeniya and Sabaragamuwa University of Sri Lanka.

It is evident that most of the students, who offer English as a second language for BA Degree of the above three universities, belong to the Upwardly Mobile Middle class. From infancy they have been exposed to an extensive use of Sinhala and frequent Code-Mixing involving a few English expressions. Their primary and secondary levels of educations have been in Sinhala. At the same time some have more opportunities to use the English language from their infancy than the students of Upwardly Mobile Middle class.

\section{Method of Data Collection}

For the selection of a corpus of language, following the guidelines offered by Ellis (1995) a sample of written works were collected from 60 students who are in the first and the second academic years of their Degree programmes. They are taught English mainly by qualified instructors and lecturers.

These students were provided with the topics 'An Unforgettable Day in Your Life' and 'My University Life' and were asked to write on it in 200 to 250 words. They were given sufficient time to write (Ellis, 1997). They started with an outline, then a first draft and a final draft.

\section{Results/Discussion}

Structurally different areas of the two languages involved would result in interference. Dulay and Burt (1974), Krashen (1982) suggest that there are two possible ways of describing the term 'interference'. One is from a psychological perspective, which suggests that there is influence from old habits when new ones are being learned. The second is from a sociolinguistic perspective which describes the language interactions which occur when two language communities are in contact. Nemser (1971) argues 'in creating Interlanguge (IL), learners sometimes make the L1 or L2 categories equivalent and sometimes they do not'.

The main findings of the study reveal that the negative L1 transfer/ interference is not only the cause for errors in the English writing of Sinhala speaking undergraduates. 
However, as Larsen - Freeman and Long (1991) identified different language errors; free variation /non systematic variation, systematic variation, developmental errors, L1 interference in the interlanguage produced by non native speakers, Sinhala speaking undergraduates' English writing cannot be categorized only under negative L1 interference.

\section{Errors in Sinhala Speaking Undergraduates' English Writing}

- Categorized under Larsen-Freeman's and Long's Classification

As revealed by the Figure 1, only $20 \%$ of the errors occur due to the influence of the L1 interference while majority of them (45\%) can be identified as developmental errors.

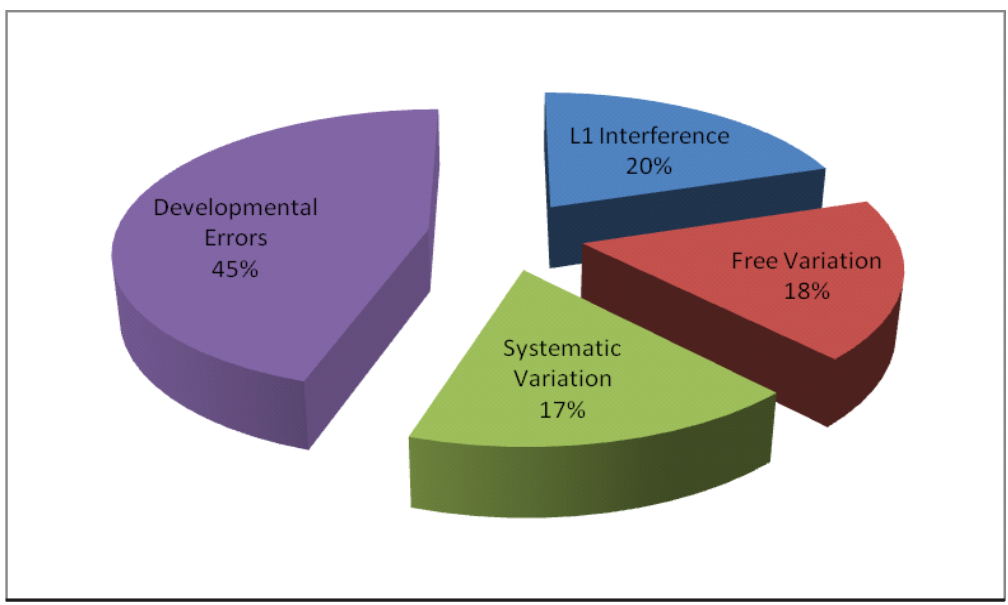

Figure :1 Errors in Sinhala speaking undergraduate English writing

Felix (1980) states an English learner of German uses the word "warum" to mean both "why" and "because". Felix points out that in Spanish or Greek, this one equivalent word does carry these two meanings. So his error would almost certainly have been identified as interference. Errors, Felix suggests, will always correspond to structures in some language.

All of this suggest that while transfer seems to be a reasonable and logical explanation for some part of the nature and form of ILs, there are certain reservations that should be born in mind. Only certain structures or forms seem to be transferable from the $\mathrm{L} 1$ and the identification of these items is further complicated by the variables of context and the individual in question.

SOV languages are generally seen to have pre posed rather than post posed 
adjectives. There is evidence and counter evidence of transfer in studies related to word order. Studies have focused on whether, for example, SVO L1s carry this pattern over into the L2. Rutherford (1986) suggests that Japanese learners do not use their L1 SOV in learning English. McNeill (1979) in fact argues for the SOV pattern as being the basic, universal word order in L1 acquisition.

The following example taken from the sample of writing conveys the influence of the LI SOV over L2 acquisition.

a) ma/ə siduvi:mə kavəda:vat amətəkəvennenæe

I(s) the incident (o) never (adv) forget (v) (example)

Subject Object Verb

Inever forget the incident. (correct)

b) vive:kə ka:ləyətulə api krikət sellamkə/a:

During the leisure

time (adv) we (s) cricket (o) play.(v) (example)

Adverbial Subject Obiect Verb

During the leisure time we play cricket. (correct)

c) antime:di api sa:dəyə sagvida:nəyəkəla:

Finally (adv) we(s) party (o) organized(v) (example)

Adverb Subject Object Verb

Finally we organized a party. (correct)

d) owun e:kətə kamətyi

They (s) it (o) liked (v) (example)

Subject Object Verb

They liked it. (correct)

Sri Lankan experience has directly influenced to use the phrases temple priest (pansale hamudhuruwo) for reverend and one at home (gedhara kena) for husband in the following sentences produced by Sinhala speaking undergraduates . This is considered as a direct translation and it effectively shows the LI interference.

a) We went to meet the temple priest.

b) She started to cry as the one at home died. 
Since 'be' verbs and 'helping verbs' are not being used in Sinhala, the English learners of Sinhala have tendency to ignore them in their writing.

a) ohu bayəuna:

Subject adjective

$\mathrm{He} \quad$ afraid (example)

He is afraid . (correct)

b) ape: visvəvidya:ləyet ehemayi subject adjective

Our university also same (example)

Our university is also same. (correct)

c) mamə satufu venəva

subject adjective

I please (example)

I am pleased (correct)

d) mamə kutuhaləyəəa patuna:|

subject adjective

I confuse (example)

I am confused. (correct)

The order of a prepositional phrase in English is preposition and then the noun governed by the preposition but in Sinhala the order is the same the opposite.

\section{/aməya ganə - Sinhala about the child - English}

"However, Sinhala speaking undergraduates are accustomed to use prepositions in clause level where prepositions are not required" (Ariyaratne, 2008) 
a) mamə e:gaenə saləkilləyomukəla:

subject preposition verb

I it about considered

I considered about it (example)

I considered it (correct)

$\begin{array}{lll}\text { b) oya: } & \text { ohu } \\ \text { subject } & & \text { preposition asked }\end{array}$

She him (from) asked

She asked from him (example)

She asked him (correct)

c) mamə mage: visvavidya:ləyə/ə a:dərəyəkərənəva subject object love

I my university to love

Ilove to my university (example)

$\mathrm{e}$

Ilove my university (correct)

a) api ekə pa:dam en $\quad$ igenəgatta

We it lesson from

learned

We learned from the lesson (example)

We learned it in the lesson. (correct)

Consequence of mixing the order of conjunctions in Sinhala with that of in English, the English learner of Sinhala tend to make mistakes by misplacing conjunctions.
a) asəni:pə
hinda
mamo
behet
conjunction
subject
object 
ill because I medicine took

I was ill because I took medicine (example)

I was ill so I took medicine [correct]

Because I was ill I took medicine. (correct)

Sinhala has different types of negative makers (NM).Therefore the verb with NM has a free word order in sentence level in Sinhala. $\begin{array}{lllll}\text { a) eya: } & \text { bat } & \text { kanne } & \text { na } & \text { Present Tense } \\ \text { subject } & \text { object } & \text { verb } & \text { NM } & \end{array}$

he/she rice eat no

Nimal does not eat rice

b) kanne na eya: bat

verb NM subject object

eat no he/she rice

Nimal does not eat rice

c) kanne na bat eya:

verb NM object subject

eat no rice he/she

Nimal does not eat rice

Following the free word order of this kind the students simply transfer Sinhala sentence structure in to English in which the word order is not fixed and make the erroneous statements as follows:

\begin{tabular}{|c|c|c|c|c|}
\hline $\begin{array}{l}\text { mamə } \\
\text { subiect }\end{array}$ & $\begin{array}{r}\mathbf{n} \boldsymbol{e} \\
\mathrm{NM}\end{array}$ & $\begin{array}{l}\text { kanne } \\
\text { verb }\end{array}$ & $\begin{array}{r}\text { bat } \\
\text { object }\end{array}$ & $\begin{array}{l}\text { haməda:mə } \\
\text { adverb }\end{array}$ \\
\hline $\begin{array}{l}\text { I } \\
\text { I }\end{array}$ & $\begin{array}{l}\text { not } \\
\text { no }\end{array}$ & $\begin{array}{l}\text { eat } \\
\text { eat }\end{array}$ & $\begin{array}{l}\text { rice } \\
\text { rice }\end{array}$ & $\begin{array}{l}\text { daily (example) } \\
\text { daily (example) }\end{array}$ \\
\hline
\end{tabular}

This incomplete application of rule makes it clear that the subjects are encountered a difficulty with the rule of insertion of auxiliary 'do' or 'does' with 'not' to form a negative in the Present Tense. As a result of that they simply add 'no' or 'not' before the verb in a negative.However, according Larsen-Freeman and Long (1991) learner's alternation between the two 
forms no and not to express the same language function is considered as free variation as it does not co-relate with any environment factors and is unpredictable in similar linguistic environment.

It is the similarities, not the differences that cause the greatest problems. (Koutsoudas and Koutsoudas 1962) According to Wode (1978) 'only if L1 and L2 have structures meeting a crucial similarity measure will there be interference, i.e. reliance on prior L1 knowledge.'

However, it is apparent that all other errors except the analyzed above cannot be categorized under L1interfernce.

Developmental errors are caused because of the learners' efforts to build up hypothesis about the language from his limited experience in the classroom. Richards classifies these errors under various heads like, overgeneralization, ignorance of rule restrictions, incomplete application of rules and false concepts hypothesized.

Richards (1971) "refers to the learner's competence at a particular time, as the transitional competence."He says that the learner's competence at a particular stage is full of what he calls as intralingual or developmental errors. These errors illustrate some of the characteristics of language acquisition. The learner's competence is transitional because it keeps changing as long as the learner tries to improve his competence. If he stops learning his competence at a particular stage becomes his final grammatical competence.

These errors are systematic and are not caused by memory lapses, fatigue and the like. These errors occur repeatedly "from one year to the next with any group of learners" (Richards,1971).

The following errors demonstrate three different developmental language errors in the sample of writing.

a) Father leaved the country after hearing the news.

b) Then I asked where is the post office?

c) I was araid and went to meet my frinds.

In the first example, the learner has overgeneralised the rule so leaved is used instead of left. The second also overgeneralises to embedded questions: Then I asked where is the post office? The third shows clear spelling mistakes. As discussed earlier all three are considered as developmental errors.

In short, language learning began to be seen as a process which involved the construction of an IL, a 'transitional competence' reflecting the dynamic nature of the learner's developing system. 
According to Larsen-Freeman and Long (1991) "the systematicty of IL consists of common developmental sequences within morpho-syntactic domain through which, with only minor variations, all learners seem to pass, regardless of age, native language or learning context." Wode (1981) was aimed at finding a universal sequence, true in essentials of all learners of all languages.

He suggested that learners go through five distinct stages of development:

1. Anaphoric sentence external: "No"

2. Non-anaphoric sentence external: "No finish"

3. Copula 'be': "That's no good"

4. Full verbs and imperatives with "don't": "You have a not fish" or "Don't say something"

5. "Do" forms: "You didn't can throw it"

(Cook, 1991)

Studies suggest that learners from different L1 backgrounds do in fact follow the developmental order suggested by Wode.

Larsen-Freeman and Long (1991) identifies another variation:Free Variation which does not correlate with any environment factors and is unpredictable in similar linguistic environment.

Mathews (1997) definition modified by Ellis (1999)

Free variation can be held to exist, when two or more variability of the same linguistic variable are seen to be used randomly by individuals with regard to all of the following.

a) Same discourse context(s)

b) Same linguistic context(s)

c) Same situational context(s)

d) Same illocutionary meaning

e) Same planning condition

IL's seem to exhibit more variability than do native languages. For example, in the sample the adult Sinhala speaking undergraduates alternate between the forms to express the same language function.

a) My sister no enter the university

b) Faculty not commence the academic programme. 
Initially, the variation in the use of these two forms is non systematic. That is the forms are used interchangeably with no apparent difference in meaning. This is considered as one source of variability with regard to the variable use of the two forms on negation, no and not.

"Learners tend to pass through stages as they acquire a particular syntactic rule or feature of the language. For example, learners acquiring negation in English as a second language begin by placing a negator in front of some sentence nucleus, such as No+drink beer for I don't drink beer. In a subsequent stage, learners place the negator within the nucleus: I no drink beer (here, don't may occur as a variant of no).Later, modals appear and the negator is attached to them. For many learners, however, the negated modal may be an unanalyzed unit, such as I can't drink beer or I won't drink beer. In the final stage, learners reach native like negation as the modal and auxiliary system comes under control." Larsen-Freeman and Long (1991)

According to Eisenstein and Madden (1982) adult ESL learners use $V$-ing and simple verb forms in a cross- sectional study in free variation, to express similar functions, (Giving me/ Give me the book etc.) It is almost certain that Sinhala speaking undergraduates' English writing indicates the learner's use of simple and progressive verb forms like:

a) Giving me what I asked for give me what I asked.

b) Taking steps to prevent... for take steps to prevent ..

"There is another type of variation that may occur from the early stagesSystematic Variation. It is evidenced when two or more sounds/grammatical forms vary contextually. Some variation is linguistically based; some is sociolinguistically determined. While ILs are indeed synchronically variable, much of the internal inconsistency is not due to free variation, systematic." Larsen-Freeman and Long (1991)

In other words, at least part of the variability can be predicted and accounted for, as due to the effect of situation, linguistic context, degree of planning, or some other identifiable cause. The same learner on a given day may alternate between supplying and omitting definite /indefinite articles, between using plural NPs with and without a plural S allomorph.

It is evident that the sample of writing provides enough examples to show that the learner is not aware of the exact place where the indefinite/definite articles are used. Therefore the learners have overgeneralised the use of indefinite/definite articles' 
a) I went (the)home and spoke to (the) Perera

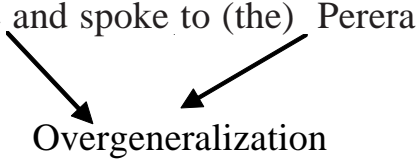

b) The students meet at night to discuss the papers as usual but that (the) particular day they did not.

Overgeneralization

Larsen-Freeman and Long (1991) terms the situation expressed above flooding. According to him it is a process by which the use of a given linguistic form is generalized to all environment, which share one feature with the environment in which the form had previously being used.

At the same time the learner provides evidence for variation in the use and nonuse of the plural /s/ even on the same lexical item.

Examples from the sample are given below.

a) Sinhalese, Tamil(s), Muslim(s) and other ethnic group(s) study together in the university.
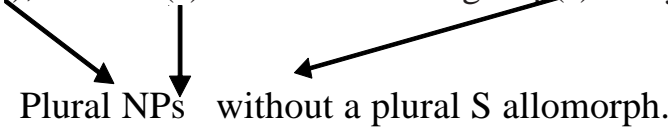

b) Usually student(s) visit the temples situated around the university.

Plural NPs with and without a plural S allomorph.

c) I never forget what soldier(s) did at that moment especially they wanted to hit the innocent civilians.

Plural NPs with and without a plural S allomorph.

d) Everybody began to shout but the teacher(s) in the classes did not even move.
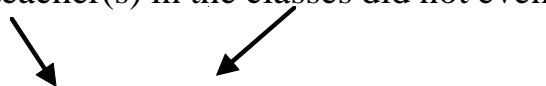

Plural NPs with and without a plural S allomorph.

\section{Conclusions}

It is evident that this highly objective and outcome oriented investigation reflects negative L1 transfer/interference is not the major cause for errors in the English writings of Sinhala speaking undergraduates. 


\section{References}

Ariyaratne, M. (2008) A Comparative Study of Word Order in Spoken Sinhala and English. Unpublished PHD thesis.

Chomsky, N. (1957) Syntactic Structures, Mouton and Co. http:www// .protile.mypace.com, Accessed on 30 ${ }^{\text {th }}$ of December 2007.

Cook, V. (1991) Second Languages Learning and Languages Teaching, London, Edward Arnold.

Corder, S.P. (1967) The Significance of Learners' Errors. Reprinted in J.C.Richards (ed.) (1974, 1984) Error Analysis: Perspectives on Second Language Acquisition. London: Longman, (Originally in International Review of Applied Linguistics, v. 5 (4), pp. 19 - 27.

Corder, S.P. (1974) Error Analysis. In J. P. B. Allen and S. Pit Corder (eds.) Techniques in Applied Linguistics (The Edinburgh Course in Applied Linguistics:3), London: Oxford University Press (Language and Language Learning), pp. 122-154.

Dulay, H. and Burt, M. (1974). You Can't Learn without Goofing. In Error Analysis. ed. J. C. Richards. London: Longman.

Eisentein, B. and Madden (1982) in Freeman, D.L and Long, M. (1991) An Introduction to Second Language Acquisition Research. New York: Longman.

Ellis, R. (1995) Understanding Second Language Acquisition. Oxford: Oxford University Press.

Ellis, R. (1997) SLA Research and Language Teaching. Oxford: Oxford University Press.

Ellis, R. (1999) Theoretical Perspectives on Interaction and Languages Learning. Accessed on $8^{\text {th }}$ of September 2009 from http:11 www. benjamins.com/egi-bin/t

Felix, S.W. (1980) The Effect of Formal Instructions on Second Language Acquisition, http:www.interscience.wiley, Accessed on $15^{\text {th }}$ of January 2008.

Gass, S. and Selinker, L. (2001) Second Language Acquisition: An Introductory Course. Mahwah, NJ: LEA, chapter 3.2.

Hegège, C. (1993) The Language Builder (Current Issues in Linguistics Theory), John Benjamins Publishing Company. 
James (1998) Errors in Language Learning, http:www//. linguistlist.org/issues. Accessed on $30^{\text {th }}$ of December 2007.

Johanson, S. (1761) in Freeman, D.L and Long, M. (1991) An Introduction to Second Language Acquisition Research. New York: Longman.

Johanson, S. (1975) The Uses of Error Analysis and Contrastive Analysis I. English Language Teaching, v. 29 (3) pp. 246- 253.

Koutsoudas and Koutsoudas (1962) in Freeman, D.L. and Long, M. (1991) An Introduction to Second Language Acquisition Research. New York: Longman.

Krashen, S. (1982) Principles and Practice in Second Language Acquisition. Oxford: Pergamon Press.

Larsen-Freeman, D. and Long, M. (1991) An Introduction to Second Language Acquisition Research. New York: Longman.

Mathews (1997) in Freeman, D.L. and Long, M. (1991) An Introduction to Second Language Acquisition Research, New York: Longman.

McNeill (1979) in Freeman, D.L. and Long, M. (1991) An Introduction to Second Language Acquisition Research, New York: Longman.

Nemser, W. (1971) Approximative System of Foreign Language Learners. http:www// eric.ed.gov, Accessed on 30 ${ }^{\text {th }}$ of November 2007.

Penman, R. (1998) Communication and the Law, Communication Research Institute of Australia, CRIA http://www.communication.org.au/html/ paper_23.html.

Richards, J.C. (ed.) (1971) Error Analysis, Perspectives on Second Language Acquisition. London: Longman.

Richards, J. (1974) A Non-Contrastive Approach to Error Analysis. In Richards, J. (Ed.). Error Analysis: Perspectives on Second Language Acquisition, Essex: Longman, pp. 172-188.

Richards, J.C. and Sampson, P. (1974) The Study of Learner English, In J.C. Richards (ed.) Error Analysis, Perspectives on Second Language Acquisition, pp. 3-18.

Rutherford, W. (1986) Grammatical Theory and L2Acquisition: a brief overview, University of California.

Selinker, B.F. (1989) Recent Issues in the Analysis of Behavior, Merill Publishing Co, Columbus, Ohio. 
Selinker and Gass (1994) Second Language Acquisition, An Introductory Course, Lawrence Erlbaum, Associates, Hillsdale.

Sridhar, S.N. (1980) Contrastive Analysis, Error analysis, and Interlanguage, IN: J. Fisiak (ed.) Contrastive Linguistics and the Language Teacher. Oxford: Pergamon Press.

Taylor, B.P. (1975) The Use of Overgeneralization and Transfer Learning Strategies by Elementary and Intermediate Students of ESL, Language Learning, 25, pp. 73-107.

Wode, H. (1978) Developmental Sequences in Naturalistic SLA in E. Hatch (ed) Readings in Second Language Acquisition, Rowleg, M.A. Newbury House.

Wode, H.(1981) in D.L Freeman, and M. Long, (1991) An Introduction to Second Language Acquisition Research. New York: Longman. 